\title{
Using Individual Positive Reinforcement Strategies to Enhance Task Completion in Children with Autism Spectrum Disorders
}

\section{Rafif A. Alsedrani \\ University of Missouri-St. Louis}

\begin{abstract}
Students with Autism Spectrum Disorders (ASD) often struggle with completing tasks in the classroom due to a myriad of reasons. One of the approaches to improve task completion with these students is to use positive reinforcement, a technique that uses a positive reward such as social praise or a tangible toy when students complete tasks correctly in order to increase that response in the future. My research question was: What happens to task completion with children with autism spectrum disorders (ASD) when the teacher focuses on appropriate individualized positive reinforcement? I went to an autism center in a Midwest city to observe teachers interacting with students while using positive reinforcement techniques. These observations, paired with teacher and parent interviews and a literature review, have led me to conclude that for my own classroom, appropriate individualized positive reinforcement would be a very successful method to improve task completion with children with ASDs. From the research, I concluded that the most important component of successful positive reinforcement with students with ASDs was to focus on reinforcements that the child preferred and that were effective, even after continued use. There is no approach that seems to work with every child, which highlights the need for appropriate individualized reinforcement to improve task completion.
\end{abstract}

Keywords: Positive Reinforcement, Autism Spectrum Disorders (ASD), Task Completion

Using Individual Positive Reinforcement Strategies to Enhance Task Completion in Children with Autism Spectrum Disorders

When I began the Master's Capstone course, one of the first readings that we completed informed me about operant conditioning techniques such as positive reinforcement (Hersen \& Rosqvist, 2005). Positive reinforcement occurs when a response is followed immediately by the presentation of a stimulus, and as a result, similar responses occur more frequently in the future (Cooper, Heron \& Heward, 2007).I was immediately fascinated by the topic and wanted to read more about it to better understand how the technique can be used in the classroom. As I learned more about operant conditioning, I realized that I wanted to understand it both theoretically and in the classroom. My educational background is with students with Autism Spectrum Disorders (ASD), so I began to brainstorm ways that I could study how to best use positive reinforcement techniques in the classroom with children with ASDs.

Studying positive reinforcement techniques in the absence of a measurable outcome is useless, I soon realized. I brainstormed different outcomes that I could measure and ultimately decided on studying task completion. I know from experience that getting children with ASD to focus on their task can be a tremendous challenge. In many cases, instead of completing a directed task they might instead not engage in the activity, making it difficult to teach them and keep them on task and learning. Since I am not currently teaching in a classroom, I sought out a classroom environment where I could observe children with ASD. I found the Autism Center. The center 
serves several counties and has varying programs that serve different needs within the autism community in a Midwest city. It has a day program for adults over the age of 21, a preschool, an in-home short term program for adults under the age of 65, and an instructional day facility. My research is with students at the instructional day facility. This instructional facility operates year-round and has 55 students. This facility provides Individualized Education Plans (IEPs), a specialized environment and certified teachers who implement individualized curricula for each child's needs and academic goals. The center partners with 11 school districts in the area. The center is a private agency that students who were enrolled in public school districts can attend in order to meet their IEPs. The classroom that I am observing has three male students (age 15 years old) and three teachers who worked with them during the week.

Watching the teachers in the classroom interact with the students led me to my research question: What happens to task completion with children with autism spectrum disorders (ASD) when the teacher focuses on appropriate individualized positive reinforcement? I will be approaching this research question from a motivation theory framework. The framework generally suggests that motivation to learn is an internal state or condition that can be influenced by both extrinsic and intrinsic factors to direct behavior. In this case, operant conditioning is the extrinsic factor that be applied in order to motivate the child to learn. The positive reinforcement would encourage the child to complete the task (learning) in order to achieve a reward that they find pleasant. In order to study this phenomenon, I constructed a plan of action that resulted in quantifiable data that I analyzed to conclude how appropriate individualized positive reinforcement can improve task completion.

\section{DATA SOURCES}

I conductedparent and teacher interviews and surveys, recorded observations in a journal, blogged during the experience, and finally conducted a behavior checklist during my six weeks of observationsessions at a small classroom with three students, each with an individual teacher, at an Autism Center. The on-task recording form allowed me to observe and measure how many times a child completed a task in a given time interval. This allowed me to compare the effectiveness of teachers using different positive reinforcement techniques with each child. The results from this action research will affect my future classroom management and my work with children with ASD. After conducting this research, I better understand how to effectively use positive reinforcement with students with ASD.

Improving task completion is a very important task with children with ASD and this seems like one of the best tools in the teacher's arsenal. One of the main conclusions that I reached was that it is extremely important for teachers to use individualized positive reinforcement; some students respond to certain reinforcers while others are not motivated at all by those same reinforcers. A teacher must really understand the likes, dislikes, preferred tasks and reinforcers for a specific student before attempting to use positive reinforcement to improve task completion.

\section{LITERATURE REVIEW}

One of the largest challenges that I have seen in classrooms of children with ASDs is the difficulty that these children have in completing tasks that the instructor has directed. Sometimes, they will disregard the instructions, be disruptive, or even participate in self injurious behavior rather than complete the task. The fields of psychology and neuroscience offer helpful and powerful theories that have been developed into techniques and strategies used by educators to help improve task completion in children with ASDs. Behaviorism is a theory developed by John Watson and B.F. Skinner that explains human behavior in terms of conditioned responses to stimuli (Moore, 2011). Teachers need to identify the set of contingencies environmentally that will most effectively trigger the desired behavior. This literature review will first examine the theory of behaviorism, then it will look 
closer at the motivation theory framework, specifically extrinsic and intrinsic motivations,and finally, it will examine relevant academic studies and articles that have examined how behavioral modification theories have been both successful and unsuccessful in changing children's behaviors and educational outcomes.

\section{Behaviorism}

Behaviorism is a psychological school of thought that tries to explain behavior through observable responses to stimuli. This is a difficult thing to do, though, because although one can observe a change to stimuli, it can be difficult to understand why behavior changes. McClelland (1987) writes, "...motivation has to do with the whyof behavior, as contrasted with the how or the what of behavior," (p. 4).Behaviorism was first introduced by American psychologist John B. Watson, who wrote that psychology, as the behaviorist views it, has the theoretical goal of predicting and controlling behavior (Watson, 1913, p. 158). He believed that behavior is a physiological reaction to stimuli in the environment. Moore (2011) said, "the principal unit of analysis for Watson was the "habit", defined as the coordinated and consistent act that develops in a given situation through repetition, rather than some supposed phenomena from mental life" (p. 451). This stimulus-response model of behaviorism propositions that it is possible to modify behavior by observing and changing stimuli to obtain a desired result.

More than 50 years after Watson's revolutionary new perspective on psychology and the principles underlying human behavior, B.F. Skinner wrote of a new direction that the field of behaviorists had undertaken: radical behaviorism. Moore (2011) wrote that Skinner's approach to a science of behavior is today known as behavior analysis and that its underlying philosophy is radical behaviorism (p. 456). In addition, one of Skinner's most famous and enduring ideas is operant conditioning. He believed that a positive reinforcer strengthens any behavior that produces it, and that a negative reinforcer strengthens any behavior that reduces or terminates it, meaning an increased likelihood of the behavior given that stimulus in the future (Skinner, 1974, p. 51). Both Skinner and Watson were also influenced by Ivan Pavlov's work with conditioned reflexes with dogs. Pavlov had learned that when a buzzer sounded at the same time as food was presented, dogs would salivate, even in later experimental conditions where only the buzzer sounded but no food was presented. The dogs had associated the buzzer with food and been conditioned to expect food when they heard the sound. Pavlov's work changed the way that people thought about human motivations and conditioning and led both Skinner and Watson to be successful in convincing some people to disregard other srfcholar's emphasis on the mind and rather focus on measurable stimuli and responses, creating a new school in psychology. The next section will investigate a theory rooted in the behaviorist tradition, which has applications to behavioral therapy.

\section{Motivation Theory}

Motivation Theory is a general term used to describe a large number of theories that seek to explain how motivation, a theoretical construct used to explain behavior, can be leveraged in order to study or influence behavior. One of the first and most famous theorists in motivation theory was Abraham Maslow (1943), the author of the seminal work $A$ Theory of Human Motivation. Maslow described every human being as having a set of needs, with physiological ones such as hunger or thirst as the largest and most fundamental needs. Only when an individual has met those needs can s/he move on to other needs such as self-actualization or self-esteem. In terms of applying that to people, Maslow (1943) found that "young children want some kind of undisrupted routine or rhythm," and that, "all people in our society, with a few pathological exceptions, have a need or desire for a stable, firmly based, (usually) high evaluation of themselves," (p. 377). Maslow's ideas about human motivation are certainly applicable to the classroom environment and especially children with ASDs. His observations about children needing routines and structures in their lives is an important one, and behavioral therapies that seek to incorporate structure and repetition seem to be the most successful, from my own observations. 
Since Maslow's writing, other academics have constructed other motivational theories of behavior that are applicable to the positive reinforcements discussed in this action research paper. For the purposes of this paper, it is important to define two different types of motivations in education: extrinsic and intrinsic. Intrinsic motivations come from a desire to improve oneself, gain knowledge or seek out challenges. Extrinsic motivations come from outside the person and result in someone performing a task or activity in order to achieve a certain outcome. The operant conditioning that Skinner pioneered is an example of extrinsic motivation: an individual will respond to a stimuli (external factor) in order to achieve a result. Some have been critical of behavioral modification techniques that focus too heavily on extrinsic motivation because they believe that it reduces the likelihood of the child performing the task independently or in being motivated in the absence of the positive reinforcement (Lepper, Greene\& Nisbett, 1973) I have seen with the students that I observe that generally the students react well to the positive behavior reinforcement but from interviewing other teachers have seen that occasionally the students lack motivation in the absence of the reinforcement.

\section{Behavior Modification}

The following section will explain how behaviorist theories of human behavior and motivation have been applied in the classroom. First, it will examine a study that was critical of behavior modification techniques. Lepper, Greene and Nisbett (1973) conducted a study that tested the hypothesis that intrinsic interest in an activity can be decreased by introducing the student to engage in that activity as an explicit way to achieve an extrinsic goal. In their study, they studied children who showed intrinsic interest in a target activity during baseline observations and then exposed them to one of three conditions: either an expected-award condition, an unexpected-award condition, or a no-award condition. Their results supported the hypothesis that the expected-award condition would show less interest later in the target activity (Lepper et al., 1973). Another researcher has found that rewards are inherently controlling, ineffective and make learning less appealing and that they do not work to foster learning (Kohn, 1995). Rewards can work well in the short term but can have unintended consequences down the road on the enjoyment of learning.

Another study sought to examine the question of whether or not rewards related to the target activity could be more successful at promoting the desired behavior than a token reward that had no relation to the target behavior. Marinak and Gambrell (2008) found that students who were given a book as a reward and students who received no reward were more likely to engage in reading subsequently than students who had received a 'token' reward. Their major conclusion was that carefully chosen rewards could encourage more reading motivation.

Although there are certainly some that are critical of behavior modification and operant conditioning in education, there is a large body of research that supports this approach, as will be illustrated in the subsequent paragraphs. Koegel and Egel (1979) conducted a study that examined the influence of corrector incorrect task completion on children's motivation to respond to tasks. The results showed that when students worked on tasks in which they were typically incorrect, their motivation to do those tasks decreased to very low levels (Koegel \& Egel, 1979). The implication here is that autistic children sometimes have low levels of correct levels, which can result in them completing even fewer tasks correctly. So, children with ASD cannot just be given rewards or positive reinforcement if they achieve the task too infrequently for it to become a recognized stimuli or if completing the task repetitively results in a lower self-esteem and even fewer correct tasks.

Keeping in line with the previous study about reading levels and the effect of rewards, another interesting study examined the functional relationship of reinforcers to other components of the operant conditioning paradigm (Williams, Kegel \& Egel, 1981). This basically means that including a more functional element to the reinforcement strategy can cause desired results. For example, placing a reward inside a container might be a better way to teach a child to open the container than just giving the child the toy when they open the container after being directed to. They found that arranging functional response relationships produced an immediate 
improvement in the child's learning.For my own research, this might have interesting implications. It seems from the literature that structuring the reward (positive reinforcement) in such a way that it makes sense functionally and is related to the task, that I can improve the student's learning outcome and task completion.

\section{Conclusion}

Behaviorism and its related theories and applications are a fascinating field of psychology. After examining the pioneers of the field, Watson and Skinner, this literature review sought to understand how their ideas had been applied with children in educational environments in both children with and without ASDs. The literature seems to suggest that the more closely that the positive reinforcement is related to the task the better that the child performs on the given task. It also seems to suggest that I should be wary of relying too heavily on positive reinforcement techniques, as they can result in decreased intrinsic motivation.

\section{Plan of Action/Methodology}

When I first began to think about what my research question would be and where I would complete the research, I was intrigued by a topic that we were discussing in one of my special education classes - positive reinforcement techniques. Initially, I think that I was skeptical and biased that these techniques wouldnot work so well with children with ASDs because I have not seen them used successfully before in a classroom I was observing in. My first challenge was coming up with a research question that would help me investigate positive reinforcement techniques better in a classroom. Initially, I think my research question was not sufficient and was outside the scope of what I could accomplish in an action research project. The research question I narrowed my line of questioning to, with input from my professor, was, "What happens to task completion with children with autism spectrum disorders when the teacher focuses on appropriate individualized positive reinforcement?" This research question was approachable and open-ended enough to allow me to really investigate what happens in the classroom when appropriate positive reinforcement techniques are used.

The second challenge was to find a setting where I could observe positive reinforcement interventions. I am not currently a teacher and do not have my own classroom, so I had to reach out to find a place that would allow me to observe the students, ask questions, and write about what I saw. AnAutism Center in a Midwest city agreed to let me conduct my research in one of their classrooms.

Once I started going to the Autism Center it helped me to plan a research design and plan of action. After watching the intervention that I investigated, appropriate positive reinforcement techniques, occur in the classroom helped me shape my research design. I knew from the beginning of this project that I would be blogging about my research to help me keep track of my ideas and projects. I also knew that I would be taking observation notes every time that I was there watching the students.I took observation notes for the entire six weeks whileI observedthreestudents at the Autism Center. When I first began going to the center, I became accustomed to the ways that they used positive reinforcement techniques in their classroom. For example, they always make sure to tell their students that they are transitioning to a new task and point out that if they complete the tasks like they ask they will be receiving some kind of reward whether it is a snack or play time with a tablet. I came up with a recording form that would allow me to look at the students every 15 seconds and observe if they were "on-task" and doing what was asked of them or if they were "off-task" and not listening or doing something else. This was not really practical with the way that the teachers engage in tasks with the students-they only give them three, four or five tasks to do at a time and then give them a reward if they complete all three correctly. So, I had to make changes to how I planned to record how often the students are "on-task". Instead, I decided to chart the number of tasks that were presented to the child and record how many of those tasks they completed. I believe that this gave me a better picture of how the students were performing at staying "on-task". However, 
there are limitations to this approach because the child can get frustrated when he does not perform a task correctly since there is no partial credit with this reductionist system with too narrow a focus.

Additionally, part of my research design was to use parent surveys and teacher interviews to better understand how the educators and parents in the children that I am observing believe positive reinforcement techniques work. I conducted interviews with three teachers who work in the classroom with the three students that I observed.Both of these surveys gave me additional insight and helped me relate what I wrote about in my literature review to what I am observing in the classroom. Here is a chart of all of the data sources that I collected and using during my action research project along with their function and relation to my research question:

\begin{tabular}{|c|c|c|c|}
\hline Data Source & When/How Collected & Analysis Strategy & $\begin{array}{c}\text { Relation to Research } \\
\text { Question }\end{array}$ \\
\hline Blog & $\begin{array}{l}\text { Weekly; Wrote a blog } \\
\text { detailing what is } \\
\text { happening with project. }\end{array}$ & $\begin{array}{l}\text { I looked back over my } \\
\text { blogs to understand how } \\
\text { the project has progressed. } \\
\text { Transcribed them and cite } \\
\text { in paper. }\end{array}$ & $\begin{array}{l}\text { Helped answer how } \\
\text { effective the process is. }\end{array}$ \\
\hline Observation Notes & $\begin{array}{l}\text { Weekly; Wrote down } \\
\text { notes during the entire } \\
\text { time I am on site (2-3 } \\
\text { hours per week). }\end{array}$ & $\begin{array}{l}\text { Used these notes to help } \\
\text { me analyze the on-task } \\
\text { recording forms and other } \\
\text { data sources. Transcribed } \\
\text { them and cite them in } \\
\text { paper. }\end{array}$ & $\begin{array}{l}\text { Showed me how } \\
\text { students respond to the } \\
\text { intervention. }\end{array}$ \\
\hline Parent Surveys & $\begin{array}{l}\text { March; Passed out to } \\
\text { parents and returned to } \\
\text { me completed. }\end{array}$ & $\begin{array}{l}\text { Analyzed this data using } \\
\text { Excel by comparing parent } \\
\text { surveys and also compared } \\
\text { them to teacher interviews. }\end{array}$ & $\begin{array}{l}\text { Used the parent answers } \\
\text { to help understand how } \\
\text { positive reinforcement } \\
\text { techniques work for their } \\
\text { children. }\end{array}$ \\
\hline Teacher Interviews & $\begin{array}{l}\text { March; } 40 \text { minute } \\
\text { interviews that I } \\
\text { transcribed in order to } \\
\text { analyze to put into my } \\
\text { final paper. }\end{array}$ & $\begin{array}{l}\text { Analyzed this data using } \\
\text { Excel by comparing it to } \\
\text { parent surveys and also } \\
\text { by investigating how what } \\
\text { they say compares to the } \\
\text { literature. }\end{array}$ & $\begin{array}{l}\text { Used these interviews } \\
\text { to understand } \\
\text { from the teacher's } \\
\text { perspective how positive } \\
\text { reinforcement works in } \\
\text { their classroom. }\end{array}$ \\
\hline $\begin{array}{l}\text { On-Task Recording } \\
\text { Form }\end{array}$ & $\begin{array}{l}\text { Weekly; I observed for } 45 \\
\text { minutes and completed } \\
\text { a form every time I } \\
\text { observe the students } \\
\text { doing their tasks. }\end{array}$ & $\begin{array}{l}\text { Inputted this data } \\
\text { into Excel to see what } \\
\text { percentage of the time } \\
\text { students are 'on-task' } \\
\text { and how that differs with } \\
\text { positive reinforcement } \\
\text { techniques. }\end{array}$ & $\begin{array}{l}\text { This information showed } \\
\text { me quantitative data } \\
\text { that is related to the } \\
\text { positive reinforcement } \\
\text { techniques in my } \\
\text { question. }\end{array}$ \\
\hline
\end{tabular}

I really am surprised by how what I have seen supports the literature that positive reinforcement techniques can help children with ASDs stay on task. The research design that I constructedallowed me to analyze what I have observed in the classroom and put it into a sort of dialogue with the literature on the subject, resulting in an action research paper that allowed me to really investigate how appropriate positive reinforcement techniques are used with children with ASDs. 


\section{Data AnAlysis}

\section{Parent Survey}

At the beginning of my observation period at the Autism Center, surveys were distributed to the parents of the students that I was observing. These surveys collected data on the student's difficulties with task completion and the parent's familiarity with positive reinforcement techniques and how successful they are with the student. The survey was composed of Likert scale questions that measured the responses, in addition to a few open-ended response questions. The table shows the parent's responses to the survey questions.

Table 1. Parent Responses to Task Completion and Positive Reinforcement Survey

5 = "Strongly Agree"; 4 = "Agree"; 3 = "Neutral"; 2 = "Disagree"; 1 = "Strongly Disagree"

$\mathrm{N}=1$

\begin{tabular}{|c|c|c|c|}
\hline Statement & Agree & Neutral & Disagree \\
\hline $\begin{array}{l}\text { My child does not have any problems with } \\
\text { completing tasks. }\end{array}$ & & & 1 \\
\hline $\begin{array}{l}\text { My child has some problems with completing } \\
\text { tasks. }\end{array}$ & & & 1 \\
\hline $\begin{array}{l}\text { My child has significant problems with } \\
\text { completing tasks. }\end{array}$ & 1 & & \\
\hline $\begin{array}{l}\text { I am familiar with behavior conditioning } \\
\text { techniques such as positive reinforcement }\end{array}$ & 1 & & \\
\hline $\begin{array}{l}\text { I use positive reinforcement* techniques with } \\
\text { my child }\end{array}$ & 1 & & \\
\hline $\begin{array}{l}\text { I think positive reinforcement is a helpful tool } \\
\text { with my child. }\end{array}$ & 1 & & \\
\hline $\begin{array}{l}\text { I think positive reinforcement does not work } \\
\text { with my child. }\end{array}$ & & & 1 \\
\hline $\begin{array}{l}\text { I have used edibles as positive reinforcement } \\
\text { with my child and it was helpful. }\end{array}$ & 1 & & \\
\hline $\begin{array}{l}\text { I have used tangibles (stickers, toys) as posi- } \\
\text { tive reinforcements with my child and it was } \\
\text { helpful. }\end{array}$ & & 1 & \\
\hline $\begin{array}{l}\text { I have used social praise as positive reinforce- } \\
\text { ment with my child and it was helpful. }\end{array}$ & & 1 & \\
\hline $\begin{array}{l}\text { I have used activities (things my child enjoys } \\
\text { doing) as positive reinforcement and it was } \\
\text { helpful. }\end{array}$ & 1 & & \\
\hline $\begin{array}{l}\text { *Positive reinforcement }=\text { an event or stimulus } \\
\text { that is presented as a consequence of behavior, } \\
\text { and then the behavior increases. }\end{array}$ & & & \\
\hline
\end{tabular}

Volume 3 
For my analysis, I combined the "Strongly Agree" and "Agree" response into the "Agree" column of the table and likewise combined the "Strongly Disagree" and "Agree" responses into the "Disagree" column. I sent the parent survey out to three parents of students who are in the classroom I observed at the autism center, but, unfortunately, only received one completed survey back,so my analysis is of the single parent whoresponded. From the survey, it is clear that the student has difficulties with task completion as the parent agreed with the statement, "My child has significant problems with completing tasks." Another important finding from the survey results are that the parent is familiar with positive reinforcement techniques and finds that some are effective with their child and others are not. In the case of the one survey respondent, edibles and activities are the two positive reinforcement techniques that the parent uses and finds helpful, as evidenced by the "Agree" responses to those related questions. Also, for this student, the parent responded "Neutral" to the question about social praise and tangibles being used with the child and being helpful. This means either that the parent has not tried them with the child or that there was no effect on the child.

Additionally, I attached a three question, open-ended response questionnaire to the Likert scale questions. The three questions were: "What kind of positive reinforcement/rewards does your child respond to?", "And, what are the most effective and appropriate reinforcers that you use with him/her?", and "Would you be willing to try different kinds of reinforcers?" Unfortunately, the one parent that did respond to the Likert scale questions gave incomplete answers to the open-ended response section so for the purposes of my analysis, I did not include it in this paper.

The parent survey responses align with my observations in the classroom, my analysis of on-task completion rates, and the relevant literature. It is extremely important that teachers use appropriate individualized reinforcers when attempting positive reinforcement to improve task completion. Some students respond better to certain positive reinforcement techniques. This illustrates the need for individualized and appropriate positive reinforcement to be used with the students.

\section{Teacher Interviews}

I conducted interviews of the teachers that work directly with the three students that I observed at the Autism Center. I looked at all of the responses to the open-ended interview questions, then coded the responses in order to tease out important similarities between the teacher responses and also to begin to establish some relevant themes. These coded interviews showed the three teachers' opinions of and experiences with positive reinforced used in their classroom. The recurring themes that unfolded showed me what these experienced educators have learned through practice on the topic of positive reinforcement. Please see Appendix J for the table with the responses, important ideas, and themes from the interviews.

From the interviews that I conducted, there were several important points. It seems that the teachers found it very important to structure the positive reinforcement differently for each child. Some students highly prefer some rewards or activities and it is important to know what the student likes in order to effectively reinforce behavior and improve task completion. However, some rewards like snacks can be unhealthy for the students so they must be limited. Also, some students need variety in their rewards because overuse of a certain kind of reward can lead to it being less effective. Additionally, some students transition poorly from one activity to another and the transition when activity time or play time is over back to school work can be extremely difficult, which almost seems to negate the positive effects of the reward increasing task completion if it causes other problems in the classroom. All of the teachers interviewed found positive reinforcement to be an important part of their classroom management and they all said that making sure that reinforcement was individualized was very important. The teachers said that they tried to insure the individualized nature of the reinforcement through learning the student's preferences and likes, which can only be accomplished by working with the student over a period of time, as it does not happen instantaneously. 
This information from the teacher interviews is supported by the literature that I read. The more appropriate and individualized that the reinforcement is the more effective that it is. This data helped me answer my research question by illustrating that individualized positive reinforcement techniques can improve task completion.

\section{Student Task Completion Rates}

During my observation sessions at the Autism Center, I would observe students during academic work time. During each lesson, whether it was reading, math or daily living skills, every time that a student was presented with a task I noted that, along with how many times they successfully completed it. I recorded these in forms and then represented the results in pie charts. See Appendix $H$ for the forms along with the charts. This analysis helped me answer my research question, as it gave me results that showed that appropriate positive reinforcement improved task completion in students with ASDs.

Each time that the teacher would begin the lesson, s/he would tell the student that it was now time for the lesson, have them sit down, then point out to them a piece of paper with three empty spaces on it and a picture of the reinforce (Week One Observation Notes, 2015). If the student completed a task correctly, he would receive a sticker on the paper. If he did this three times and received three stickers, then he was rewarded with the reinforcer pictured. The reinforcer could be time with an iPad, break time, a snack, or another preferred activity or item. Throughout the tasks, the teacher would periodically remind the student that he just needed one or two more stickers to receive the reinforcer (Week One Observation Notes, 2015). In addition to the reinforcer pictured, the teacher also used social praise as a reinforcereach time that the student completed a task correctly. The teacher might say, "Good job”, "Great", or "I am so proud of you" (Week Two Observation Notes, 2015). The following charts show the three students completion rates from three different dates: $3 / 16 / 2015$, $3 / 31 / 2015$, and $4 / 8 / 2015$. The "Task Completed" can be defined for my purposes as answering the teacher's prompt correctly within a reasonable amount of time. A wrong answer or a non-answer would be considered "Not Completed".

\section{Chart 1: Student's Completion Rates}

These graphs show that the studentsgenerally successfully complete the tasks presented. The reminder of the reinforcement both before and during the task seems to keep the child on-task and these rates are very positive. It is difficult to contrast these results with a baseline observation since the teachers always use the positive reinforcement during lessons and I was unable to observe the students during academic lessons when the positive reinforcement was not being used. I can hypothesize, though, that the students' task completion rates would be lower if positive reinforcement was not being used during the tasks. During the sessions, the children become visibly excited when they receive the reward at the end of the task (Week One Observation Notes, 2015). The majority of the time the student completed the tasks correctly and stayed focused on the task. I can safely conclude that the positive reinforcement is successful in keeping the students engaged in the task.

These charts just illustrate graphically what I have been observing in the classroom-that individualized positive reinforcement helps improve task completion with these students. Across the board the results were pretty similar, generally the students complete tasks successfully. It just shows me that this technique really is successful and that I should use it in my future classroom.

\section{IMPLICATIONS}

Before I carried out this research and these interviews, I was a little skeptical of how effective this positive reinforcement would be because in Saudi Arabia, where I am from, I have not seen it used as effectively as it was used at the Autism Center. I was shocked by how the use of prompts, visual schedules, and reinforcement after each task really got the children to focus on the task and not engage in destructive or aggressive behavior.I was 
really surprised by how the positive reinforcement affects the student's work. The student's task completion rates were upwards of $80 \%$ during the sessions that I observed at the Autism Center (Appendix H), which is a very good task completion rate for students with ASD. Although I did not have baseline data to compare the high task completion rates to, I argue that this high task completion rate is higher than the rates would have been if there was no positive reinforcement being used to teach the students to stay engaged in and complete the tasks presented.It is amazing that if we know the individual appropriate positive reinforcers we can teach the student's to complete and stay engaged in the task (Personal Blog, 4/7/2015).

Both the parent survey and the teacher interviews confirmed that those involved in the student's upbringing and education believe that positive reinforcement helps the student with task completion. One of the major implications from the research I conducted was that some reinforcers work for some children better than others. A student might be motivated by activities or edibles but not by tangible rewards (Table 1: Parent Responses to Task Completion and Positive Reinforcement Survey). Knowing the child's preferred activities and reinforcers is crucial in developing any kind of behavior modification plan that involves positive reinforcement.

Another major implication that I learned from the teacher interviews and from observing the students was that over time, reinforcer's effectiveness can fade. One of the teachers who I interviewed said, "Variety of any technique is important to keep students and staff engaged...repetitive use of any single reinforcer tends to devalue over time, even if reinforcer remains highly preferred overall. I avoid reinforcers becoming conditionally reinforced" (Appendix J). The implication here is that even if the student still prefers the reinforcer, it is important to vary the reinforcer. This really points to the need for teachers to stay engaged with the student and to know when a reinforcer starts to become less effective than before.

A final implication from this research is that social praise as a reinforcer should be used earnestly, consistently, and frequently. Across the board, all the teachers interviewed said that students and staff like social praise but it is difficult to consistently give authentic social praise (Appendix J).The teachers believe that social praise is effective but can have negative side effectives. A negative side effect can be that students can gauge when teachers are praising them in an empty, repetitive manner, and it is less effective. It can take a lot of effort and concentration to give consistent social praise (Appendix J). I saw that teachers consistently gave social praise during work time with students. It seemed to help build a positive relationship between the student and the teacher. Successful task completion was almost always immediately followed by verbal social praise (Week Two Observation Notes, 2015).

In conclusion, the individualized appropriate positive reinforcement resulted in high task completion rates in the students that I observed at the Autism Center. Although it seems like a simple concept - reward the student for successful work in order to increase the likelihood that the student will do the same in the future - teachers need to stay engaged with the student, know what reinforcers work for the student, do not overuse any single reinforcer, and attempt to give authentic social praise.

\section{RECOMMENDATIONS}

Teachers who work with students with ASD should absolutely consider positive reinforcement as an excellent way to improve task completion rates. There are several things that teachers need to keep in mind though when using positive reinforcement with the students. First, teachers should use social praise at every step with the student. Rewarding the students with social praise is an easy and effective way to improve task completion rates. Also, it is enjoyable for the teacher to verbally reward the student when s/he completes a task. However, one must be careful to not give social praise that seems inauthentic or forced as students realize this and are less likely to want to engage in the task. There is no one size fits all approach to delivering authentic and genuine social praise to a student. Teachers just need to stay mindful that students can tell when a teacher is giving forced or inauthentic praise and attempt to always deliver genuine social praise. 
Second, teachers should observe and work with the student in order to determine preferred activities, snacks, or tangibles that the student is motivated by the most in order to effectively reinforce the student to stay engaged and focused on a task. Different reinforcers motivate different students and these preferences can change over time. What works in September might not work in January. Staying abreast of the student's changing preferences is important for the teacher.

In addition, over time, reinforcers can be over-used and their effectiveness can fade, which means that teachers need to vary the reinforcers with the student. Relying on a single preferred activity or snack would result in that reinforcer losing its effectiveness in improving task completion. Also, overusing edible reinforcers can be detrimental to the student's health. Obesity and diabetes are concerns for students and edible snacks, although preferred, should be limited so that they do not contribute to those problems. Teachers should attempt to either use healthier edible reinforcers that the student still prefers, or not frequently use edible reinforcers.

\section{REFERENCES}

Cooper, J. O., Heron, T. E., \& Heward, W. L. (2007). Applied Behavior Analysis. (2nd ed., pp. 1-678). Pearson.

Hendricks, C. (2013). Improving Schools Through Action Research (3rd ed., pp. 1-193). Pearson.

Koegel, R. L., \& Egel, A. L. (1979). Motivating autistic children. Journal of Abnormal Psychology, 88(4), 418-426.

Kohn, A. (1995). The risk of rewards. Brown University Child \& Adolescent Behavior Letter, 11(2), 8.

Lepper, M. R., Greene, D., \& Nisbett, R. E. (1973). Undermining children's intrinsic interest with extrinsic reward: A test of the 'overjustification' hypothesis. Journal of Personality and Social Psychology, 28(1), 129-137.

Marinak, B. A., Gambrell, L. B. (2008). Intrinsic motivation and rewards: What sustains young children's engagement with text? Literacy Research and Instruction. 47(1).

Maslow, A. H. (1943). A theory of human motivation. Psychological Review, 50(4), 370-396.

McClelland, D. (1987). Human Motivation. New York: CambridgeUniversity Press.

Moore, J. (2011). Behaviorism. Psychological Record, 61(3), 449-465.

Skinner, B. (1974). About behaviorism. New York: Knopf; [distributed by Random House].

Watson, J. B. (1913). Psychology as the behaviorist views it. Psychological Review, 20(2), 158-177.

Williams, J. A., Koegel, R. L., \& Egel, A. L. (1981). Response-reinforcer relationships and

improved learning in autistic children. Journal of Applied Behavior Analysis, 14(1), 53-60.

Citation: Rafif A. Alsedrani, “Using Individual Positive Reinforcement Strategies to Enhance Task Completion in Children with Autism Spectrum Disorders". American Research Journal of Humanities and Social Sciences, Volume 3, 2017; pp:1-11

Copyright (c) 2017 Rafif A. Alsedrani, This is an open access article distributed under the Creative Commons Attribution License, which permits unrestricted use, distribution, and reproduction in any medium, provided the original work is properly cited. 